\title{
Antioxidant Activities of Extracts from Sarcocarp of Cotoneaster multiflorus
}

\author{
Xiangping Liu, ${ }^{1}$ Jia Jia, $^{2}$ Xuemin Jing, ${ }^{1}$ and Guoliang Li (iD) ${ }^{1}$ \\ ${ }^{1}$ College of Animal Science and Veterinary Medicine, Heilongjiang Bayi Agricultural University, Daqing 163319, China \\ ${ }^{2}$ Preclinical Medicine Department, Daqing Medical College, Daqing 163319, China \\ Correspondence should be addressed to Guoliang Li; liguoliang3885@163.com
}

Received 9 February 2018; Accepted 5 April 2018; Published 13 May 2018

Academic Editor: Sevgi Kolaylı

Copyright ( 2018 Xiangping Liu et al. This is an open access article distributed under the Creative Commons Attribution License, which permits unrestricted use, distribution, and reproduction in any medium, provided the original work is properly cited.

\begin{abstract}
The ethanol-water $(7: 3, \mathrm{v} / \mathrm{v})$ extract of Cotoneaster multiflorus sarcocarp was sequentially fractionated by liquid-liquid partition using $n$-hexane, diethyl ether, methylene dichloride, and ethyl acetate. The contents of total polyphenols, total flavones, and oligomeric proanthocyanidins in the five parts (including the ethanol-water extract) were determined. In addition, 2,2-diphenyl1-picrylhydrazyl free radical-scavenging, 2,2-azino-bis(3-ethylbenzothiazoline-6-sulfonic acid) diammonium salt radical cation decolorization, reducing power, ferric reducing antioxidant power, and lipid peroxidation inhibition assays were conducted to test the antioxidant activities of Sample 1 (the ethanol-water fraction) and Sample 2 (the ethyl acetate fraction) in vitro. In the above five assays, Sample 2 showed greater antioxidant capacities than Sample 1. Furthermore, Sample 2 was better able to protect low-density lipoproteins from oxidation in a dose-dependent manner. The test results show that $C$. multiflorus sarcocarp, especially the ethyl acetate-soluble fraction, may be a potential source of natural antioxidants.
\end{abstract}

\section{Introduction}

Free radicals are atoms or groups with unpaired electrons, and they are generally unstable and highly reactive. The most common free radicals are oxygen-reactive species, such as singlet oxygen, hydrogen peroxide, hydroxyl radical, carboxyradical, and superoxide radical, which have the greatest biological significance $[1,2]$. The oxygen-reactive species generated in the human body can cause oxidative damage associated with membrane damage, aging, heart disease, and cancer $[3,4]$. There is growing interest in phytochemicals, which have been hailed as "a gift from plants to humans," as they have various health benefits and may be a new source of natural antioxidants [5, 6]. People look for natural antioxidants and use them in pharmaceutical preparations, foods, and cosmetics to replace synthetic antioxidants due to their potential health risks and toxicity $[7,8]$. The application of natural antioxidants can effectively improve the stability of foods, nutrients, and drugs and at the same time enhance the body's anti-inflammatory, antiallergic, and antitumor capacities via the polyphenolic characteristics of these antioxidants [9]. Many studies have shown that natural antioxidants in plants are usually derived from polyphenols, flavonoids, and proanthocyanidins. The antioxidant activities of the extracts are positively correlated with their contents of polyphenols, flavonoids, or proanthocyanidins [10, 11]. The plants having high phenolic compounds contents were proved to be a good source of powerful antioxidants [12]. Finding new, effective natural antioxidants is an important research topic. The isolation and purification procedures for pure compounds are often expensive and time-consuming and require considerable resources. The evaluation of the antioxidant activities of the extracts and fractions is regarded as a required step due to their potentials for high antioxidant potency [13].

The genus Cotoneaster plant that belongs to the Rosaceae family is broadly distributed in Asia and Europe [14-16]. There are over 50 species in this genus found in China, and many of these species are found in the Chinese provinces of Yunnan and Sichuan $[14,17]$. Many Cotoneaster species have become popular ornamental plants due to their attractive foliage and abundant flowers and in particular for their 
bright red fruits [18]. Various species of the genus Cotoneaster are used in the treatment of bronchitis, gastritis, vasculitis, and wound infections $[15,19]$. As ornamental plants, few studies on the phytochemical properties and utilization of the genus Cotoneaster have been conducted. Some flavonoid constituents from $C$. wilsonii leaves were identified by Chang and Jeon [14] and Chumbalov et al. [20]; many phenolic glycosides were isolated and identified from $C$. orbicularis by El-Mousallamy et al. [21]; the flavonol and isoflavones from C. simonsii were studied and the flavonoid glycoside composition in C. thymaefolia was determined by Palme et al. [19]; the proanthocyanidins in C. oligantha were identified by Pashinina et al. [22]. C. multiflorus is an ornamental plant that is widely distributed in China, Korea, and Europe; it is a fruitbearing shrub with strong branches and deciduous leaves that is rich in nutrients and is a wild fruit tree resource that is still underexplored $[23,24]$. To date, the pharmacological effects and chemical composition of various species of the genus Cotoneaster have been reported, but to the best of our knowledge the chemical components and related activities of C. multiflorus have not been reported.

The aim of the study was to measure the total polyphenols, total flavonoids, and the oligomeric proanthocyanidins contents in C. multiflorus sarcocarp, which directly impact its antioxidant activity, determine the optimal solvents for partitioning, and evaluate the in vitro antioxidant capacity of the sarcocarp extracts.

\section{Experimental}

2.1. Plant Material. Fresh fruits were manually picked from similar 3 m, 15-year-old C. multiflorus trees in October 2017 from the outskirts of Harbin, Heilongjiang Province, China. The material was identified by Professor Huiyan $\mathrm{Gu}$ of the Forestry College, Northeast Forestry University, China, and voucher specimens were placed in the herbarium. To keep the material stable, $1 \mathrm{~kg}$ picked ripe red fruits were stored in plastic bags in a freezer at $-18^{\circ} \mathrm{C}$ until the experiment began. The moisture content of the $C$. multiflorus sarcocarps was $76 \% \pm 4 \%$, and this value was used in every step of the following experiments.

2.2. Chemicals. Folin-Ciocalteu reagent, 2,2-azino-bis(3ethylbenzothiazoline-6-sulfonic acid) diammonium salt (ABTS), 2,4,6-tripyridyl-s-triazine (TPTZ), 6-hydroxy2,5,7,8-tetramethylchroman-2-carboxylic acid (Trolox), 2,2diphenyl-1-picrylhydrazyl (DPPH), butylated hydroxytoluene (BHT), butylated hydroxyanisole (BHA), and $L$-ascorbic acid (L-AA) were purchased from Sigma Chemical Co. (St. Louis, MO, USA). Rutin and grape seed extracts (90\%) were obtained from Tongtian Bio-Tech Co. (Shanghai, China).

2.3. Extraction Process. The pulp of the fresh fruits of $C$. multiflorus was separated from the seeds, and $20 \mathrm{~g}$ of the pulp was extracted with $200 \mathrm{~mL}$ of ethanol-water $(7: 3, \mathrm{v} / \mathrm{v})$ for $24 \mathrm{~h}$ in a $500 \mathrm{~mL}$ round-bottomed flask in shaking water bath at $25^{\circ} \mathrm{C}$. Then, the filtered solution was concentrated using a rotatory evaporator (Shensheng Biotech Co., Ltd.,
Shanghai, China) at $55^{\circ} \mathrm{C}$ and $-0.09 \mathrm{MPa}$ until the volume of the solution remained approximately steady. The aqueous suspension was partitioned into five fractions. One fraction was directly frozen to afford a powder, and this was taken as Sample 1. The other four fractions were reextracted with the same volume of ethyl acetate, $n$-hexane, ether, and methylene dichloride. The organic phases were dried under reduced pressure with a rotatory evaporator. These dried powders were named Sample 2, 3, 4, and 5, respectively. These samples were stored in a desiccator protected from light until further use.

2.4. Measurement of the Total Polyphenols. The FolinCiocalteu colorimetric method was used to estimate the total phenolic content in the C. multiflorus extracts and fractions based on the procedure of Velioglu et al. [25] with a slight modification. Briefly, $1 \mathrm{~mL}$ of each sample was mixed with $1 \mathrm{~mL}$ of Folin-Ciocalteu reagent which was diluted by a factor of two using distilled water prior to use. Subsequently, the mixtures were gently oscillated and held at room temperature for $4 \mathrm{~min}$. After that, $1 \mathrm{~mL}$ of freshly prepared $10 \%(\mathrm{w} / \mathrm{w})$ $\mathrm{Na}_{2} \mathrm{CO}_{3}$ solution was added to each sample. Then, the mixed solution was diluted with deionized water to a final volume of $25 \mathrm{~mL}$ and stored at room temperature for $2 \mathrm{~h}$. Then, we measured the absorbance of the solution at $765 \mathrm{~nm}$ using a spectrophotometer (UV-5500PC, Shanghai Metash Instrument Co., Ltd., China). We calculated the total polyphenols content using a calibration curve, and gallic acid was used as the reference substance for preparing the calibration curve. The total polyphenols content is expressed as gallic acid equivalents (GAE) in $\mathrm{mg} / \mathrm{g}$ samples.

2.5. Measurement of the Total Flavonoids. The total flavonoids (TF) content of each sample was determined by a colorimetric method as described in the literature [26] with a slight modification. In brief, each sample $(1 \mathrm{~mL})$ was mixed with $2 \mathrm{~mL}$ of distilled water and $0.5 \mathrm{~mL}$ of sodium nitrite $(5 \%)$. The mixtures were gently oscillated and allowed to stand at room temperature for $6 \mathrm{~min}$. After that, $0.5 \mathrm{~mL}$ of aluminum nitrate $(10 \%)$ was added to the mixed solutions, and they were left to stand for an additional $6 \mathrm{~min}$. Then, $2.5 \mathrm{~mL}$ of sodium hydroxide (5\%) was added. After $15 \mathrm{~min}, 2.5 \mathrm{~mL}$ of distilled water was added to make the final volume $9 \mathrm{~mL}$, and the absorbance of the dilute solution was measured at $500 \mathrm{~nm}$ using a spectrophotometer. Rutin was used as the standard. The total flavonoids content is expressed as rutin equivalents (RE) in $\mathrm{mg} / \mathrm{g}$ samples.

2.6. Measurement of the Oligomeric Proanthocyanidins (OPC). The OPC content of each sample was determined by the $n$ butyl alcohol-hydrochloric acid method [27]. The samples $(1 \mathrm{~mL})$ were mixed with $0.2 \mathrm{~mL}$ of ammonium ferric sulfate ( $2 \%$ in $2 \mathrm{M}$ hydrochloric acid) and $6 \mathrm{~mL}$ of $n$-butyl alcoholhydrochloric acid $(95: 5, \mathrm{v} / \mathrm{v})$. Then, the mixture was incubated in a water bath at $95^{\circ} \mathrm{C}$ for $40 \mathrm{~min}$. After cooling, the absorbance of the solution was determined at $546 \mathrm{~nm}$. The extract of grape seeds (90\%) was used as the standard. 


\subsection{Determination of the Antioxidant Activity}

2.7.1. DPPH Free Radical-Scavenging Activity Assay. The radical-scavenging activities of the samples were measured according to the method described by Yang et al. [28] with a slight modification. Briefly, $0.4 \mathrm{~mL}$ of the samples at various concentrations $(0.1-0.2 \mathrm{mg} / \mathrm{mL})$ was added to $3 \mathrm{~mL}$ of DPPH solution $(25 \mu \mathrm{g} / \mathrm{mL})$ as the free radical source and left to stand for $30 \mathrm{~min}$ at room temperature. Then, the absorbance of each solution was determined at $517 \mathrm{~nm}$. The same concentrations of L-AA, BHA, and BHT were used as references to compare with the activities of the plant extracts. The DPPH radical-scavenging activity was calculated using the following equation:

$$
I=\left(1-\frac{A_{1}}{A_{0}}\right) \times 100 \% .
$$

$I$ is inhibition ratio, $\mathrm{IC}_{50}$ is half of the maximum inhibitory concentration; $A_{0}$ is the absorbance of the control; $A_{1}$ is the absorbance of the sample

2.7.2. ABTS Radical Cation Decolorization Assay. The ABTS radical-scavenging activities of the samples were determined according to the method described by Arnao et al. [29] with a slight modification. The working solution was prepared by mixing equal volumes of $7.4 \mathrm{mM}$ ABTS solution and $2.6 \mathrm{mM} \mathrm{K}_{2} \mathrm{~S}_{2} \mathrm{O}_{8}$ solution and leaving the mixture to stand at room temperature for $12 \mathrm{~h}$ in the dark. A $1 \mathrm{~mL}$ aliquot of the mixed solution was added to $47 \mathrm{~mL}$ of methanol to obtain a solution with an absorbance of $7.0 \pm 0.02$ units at $744 \mathrm{~nm}$. Fresh ABTS solution was prepared for each assay. Aliquots of $0.15 \mathrm{~mL}$ of solutions of different concentrations $(0.047-0.1 \mathrm{mg} / \mathrm{mL})$ were added to $2.85 \mathrm{~mL}$ of ABTS solution, and the mixture was left at room temperature for $2 \mathrm{~h}$ in the dark. Different concentrations of L-AA, BHA, and BHT were used as reference experiments to compare with the activities of the plant extracts. The absorbance at $744 \mathrm{~nm}$ was determined using a spectrophotometer. A standard curve of Trolox in concentrations ranging from 50 to $600 \mu \mathrm{M}$ was prepared. The ABTS radical-scavenging activity is expressed as $\mu \mathrm{mol}$ Trolox equivalents (TE)/g extracts.

2.7.3. Reducing Power Assay. The reducing power of the extracts of the sarcocarp of $C$. multiflorus was measured according to method of Liu et al. [30]. Solutions of the samples at different concentrations $(0.2-0.04 \mathrm{mg} / \mathrm{mL})$ were mixed with $2.5 \mathrm{~mL}$ of $0.2 \mathrm{~mol} / \mathrm{L}$ phosphate buffer ( $\mathrm{pH} \mathrm{6.6)}$ and $2.5 \mathrm{~mL}$ of a $1 \%(\mathrm{w} / \mathrm{v}) \mathrm{K}_{3}\left[\mathrm{Fe}(\mathrm{CN})_{6}\right]$ solution. The mixture was incubated for $20 \mathrm{~min}$ at $50^{\circ} \mathrm{C}$ in a water bath. After cooling, $2.5 \mathrm{~mL}$ of $10 \%(\mathrm{w} / \mathrm{v}) \mathrm{Cl}_{3} \mathrm{CCOOH}$ solution was added and centrifuged at $3000 \times \mathrm{g}$ for $10 \mathrm{~min}$. A $2.5 \mathrm{~mL}$ aliquot of the upper layer was combined with $2.5 \mathrm{~mL}$ of deionized water and $0.5 \mathrm{~mL}$ of $0.1 \%(\mathrm{w} / \mathrm{v}) \mathrm{FeCl}_{3}$ solution. After allowing the mixture to stand at room temperature for $10 \mathrm{~min}$, the absorbance was determined at $707 \mathrm{~nm}$. L-AA, BHA, and BHT were used as reference compounds. The absorbance of the reaction mixture was positively correlated with the reducing power.
2.7.4. Ferric Reducing Antioxidant Power (FRAP) Assay. The FRAP assay is based on determining the antioxidant potentials of the samples through the reduction of the $\mathrm{Fe}^{3+}$ TPTZ complex to $\mathrm{Fe}^{2+}$-TPTZ by the presence of antioxidants according to the procedure described by Benzie and Strain [31]. The working solution was prepared freshly by mixing $2.5 \mathrm{~mL}$ of $20 \mathrm{mmol} / \mathrm{L} \mathrm{FeCl}_{3}$ solution, $2.5 \mathrm{~mL}$ of $10 \mathrm{mmol} / \mathrm{L}$ TPTZ solution, and $25 \mathrm{~mL}$ of $300 \mathrm{mmol} / \mathrm{L}$ acetate buffer $(\mathrm{pH}$ 3.6). This solution was incubated at $37^{\circ} \mathrm{C}$ for $30 \mathrm{~min}$ and was used as the FRAP working solution. Different concentrations of sample solutions $(0.15 \mathrm{~mL})$ were reacted with $2.85 \mathrm{~mL}$ of FRAP solution for $30 \mathrm{~min}$ in a dark place. The absorbance of the $\mathrm{Fe}^{2+}$-TPTZ complex was measured at $593 \mathrm{~nm}$. L-AA, $\mathrm{BHA}$, and BHT were used as positive controls. A standard curve was prepared using Trolox concentrations in the range of 50 to $600 \mathrm{mmol} / \mathrm{L}$. The ferric reducing antioxidant activity is expressed as $\mu \mathrm{mol}$ Trolox equivalents (TE)/g extracts.

2.8. Lipid Peroxidation Inhibition Assay. The oxidative deterioration of the samples was investigated using the Schaal oven test according to Economou et al. [32]. Solutions of the samples at different concentrations $(10,20,40$, and $80 \mu \mathrm{g} / \mathrm{mL}$ of the samples) were added to $50 \mathrm{~mL}$ of sunflower oil. Then, the oil samples were put in an oven at $65^{\circ} \mathrm{C}$ for $72 \mathrm{~h}$. A blank sample was subjected to the same conditions without adding any additives. The absorbance was determined at $538 \mathrm{~nm}$. The rate of autoxidation of the sunflower oil was measured based on the increase in 2-thiobarbituric acid-reactive substances (TBARS). L-AA, BHT, and BHA were used as references for comparison. The contents in TBARS in untreated and treated samples were used to calculate the inhibition of lipid oxidation using the following equation:

$$
I=\left(1-\frac{A_{1}}{A_{0}}\right) \times 100 \% .
$$

$I$ is inhibition ratio; $A_{0}$ is the absorbance of the control; $A_{1}$ is the absorbance of the sample.

\section{Results and Discussion}

3.1. Total Polyphenols (TP), Total Flavonoids (TF), and Oligomeric Proanthocyanidins (OPC) Contents. The proportions of total polyphenols (TP), total flavonoids (TF), and oligomeric proanthocyanidins (OPC) for the five different extracts from the fresh sarcocarp of C. multiflorus using different extraction solvents are shown in Table 1. Among the five samples, the highest contents of TP, TF, and OPC were found in Sample 2 (extracted with ethyl acetate), whereas the lowest contents of all three components were found in Sample 3 (extracted with $n$-hexane) based on the extraction efficiency. After partitioning into ethyl acetate, the concentrations of TP, TF, and OPC increased from $80.7 \pm 3.9 \mathrm{mg} \mathrm{GAE} / \mathrm{g}$, $112.4 \pm 5.4 \mathrm{mg} \mathrm{RE} / \mathrm{g}$, and $251.0 \pm 12.2 \mathrm{mg} \mathrm{GSEE} / \mathrm{g}$ (in Sample 1) to $155.1 \pm 7.5 \mathrm{mg} \mathrm{GAE} / \mathrm{g}, 226.9 \pm 11.0 \mathrm{mg} \mathrm{RE} / \mathrm{g}$, and $328.7 \pm 15.5 \mathrm{mg} \mathrm{GSEE} / \mathrm{g}$ (in Sample 2, based on the extraction efficiency), respectively. The increases in the concentrations of TP, TF, and OPC are significant $(P<0.05)$, which might indicate that most of the polyphenols, flavonoids, and 
TABLE 1: Total polyphenol (TP), total flavonoid (TF), and oligomeric proanthocyanidins (OPC) content of five fractions from C. multiflorus sarcocarp (values are mean \pm SD of three replicate determinations).

\begin{tabular}{lccccccccc}
\hline \multirow{2}{*}{ Sample } & \multicolumn{3}{c}{$\begin{array}{c}\text { TPC (gallic acid equivalents } \\
\text { (GAE) in mg/g samples) }\end{array}$} & \multicolumn{3}{c}{ TFC (rutin equivalents (RE) in } & \multicolumn{4}{c}{$\begin{array}{c}\text { OPCC (grape seed extract } \\
\text { mg/g sample) }\end{array}$} \\
& FWB & DWB & EPB & FWB & DWB & EPB & FWB & DWB & EPB \\
\hline Sample 1 & $14.8 \pm 0.7$ & $38.6 \pm 1.7$ & $80.7 \pm 3.9$ & $20.6 \pm 0.9$ & $53.7 \pm 2.2$ & $112.4 \pm 5.4$ & $46.0 \pm 1.8$ & $120.0 \pm 5.5$ & $251.0 \pm 12.2$ \\
Sample 2 & $6.7 \pm 0.3$ & $17.5 \pm 0.8$ & $155.1 \pm 7.5$ & $9.8 \pm 0.5$ & $25.6 \pm 1.0$ & $226.9 \pm 11.0$ & $14.2 \pm 0.7$ & $37.0 \pm 1.5$ & $328.7 \pm 15.5$ \\
Sample 3 & $0.3 \pm 0.0$ & $0.9 \pm 0.0$ & $50.0 \pm 1.6$ & $0.3 \pm 0.0$ & $0.8 \pm 0.0$ & $45.6 \pm 1.9$ & $0.9 \pm 0.0$ & $2.3 \pm 0.1$ & $129.4 \pm 5.6$ \\
Sample 4 & $4.6 \pm 0.2$ & $12.0 \pm 0.5$ & $122.3 \pm 4.6$ & $5.7 \pm 0.2$ & $14.9 \pm 0.7$ & $151.6 \pm 7.3$ & $6.4 \pm 0.2$ & $16.7 \pm 0.9$ & $170.2 \pm 7.8$ \\
Sample 5 & $0.3 \pm 0.0$ & $0.7 \pm 0.1$ & $17.1 \pm 0.8$ & $0.2 \pm 0.0$ & $0.6 \pm 0.0$ & $13.8 \pm 0.6$ & $0.3 \pm 0.0$ & $0.7 \pm 0.1$ & $18.4 \pm 0.9$ \\
\hline
\end{tabular}

FWB: fresh weight basis; DWB: dry weight basis; EPB: extracted powder basis. ${ }^{a}$ Total polyphenol content, expressed in milligrams of gallic acid equivalents per gram. ${ }^{b}$ Total flavonoids content, expressed in milligrams of rutin equivalents per gram. ${ }^{c}$ Total oligomeric proanthocyanidins content, expressed in milligrams of grape seed extract equivalents per gram. Sample 1: the crude power extracted with ethanol-water $(7: 3, \mathrm{v} / \mathrm{v})$. Sample 2: the power reextracted from Sample 1 with ethyl acetate. Sample 3: the power reextracted from Sample 1 with n-hexane. Sample 4: the power reextracted from Sample 1 with ether. Sample 5: the power reextracted from Sample 1 with methylene dichloride.

oligomeric proanthocyanidins in the ethanol-water extract were more soluble in a less polar solvent, such as ethyl acetate. Ethyl acetate is an ester that can be found in fruit and wine. Ethyl acetate is manufactured in industry mainly via the reaction of ethanol and acetic acid. Due to its low toxicity, it is commonly used in extractions as a solvent. Ethyl acetate fractions were verified to be safe by acute toxicity study [33]. Therefore, the two samples with the highest contents of TP, TF, and OPC (Sample 1, Sample 2) were chosen for the following antioxidant activity assays.

\subsection{Antioxidant Activity}

3.2.1. DPPH Radical-Scavenging Activity. The DPPH method has been used extensively to screen for antioxidant activity in vitro, and it is sufficiently sensitive to be detected at low concentrations $[34,35]$. The DPPH radical-scavenging activities of different concentrations of Sample 1, Sample 2, and the three standard solutions (butylated hydroxyanisole (BHA), butylated hydroxytoluene (BHT), and L-ascorbic acid (L-AA)) are shown in Figure 1. In addition, the $\mathrm{IC}_{50}$ was calculated from the equation of the regression curve. It can be seen that the two samples exhibited varying degrees of scavenging capacities. Sample 2 showed greater activity in a dosedependent manner and showed an $\mathrm{IC}_{50}$ value of $42.72 \mu \mathrm{g} / \mathrm{mL}$, which is higher than that of Sample 1 (the $\mathrm{IC}_{50}$ could not be determined from the regression equation) and comparable to those of BHA $(34.39 \mu \mathrm{g} / \mathrm{mL})$, BHT $(40.75 \mu \mathrm{g} / \mathrm{mL})$, and LAA $(40.74 \mu \mathrm{g} / \mathrm{mL})$. The increase in these curves illustrates that more concentrated solutions of these compounds have greater DPPH radical-scavenging activities. The results show that some or all of the components of the ethyl acetate fraction have significant strong DPPH radical-scavenging activities in vitro. Similar results have been reported in the literature [36].

3.2.2. ABTS Radical-Scavenging Activity. The ABTS assay is an elegant method for investigating the antioxidant activity of chain-breaking antioxidants and of hydrogen-donating antioxidants [37]. The results with various concentrations of the two samples and the three standard solutions (BHA, BHT,

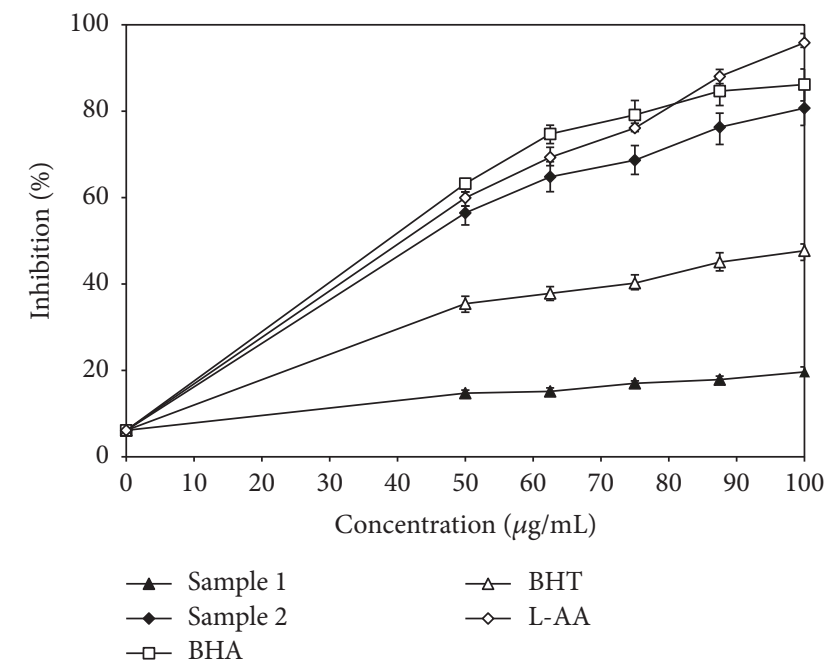

FIgURE 1: Free radical-scavenging activity of extracts from $C$. multiflorus sarcocarp measured by DPPH assay. Sample 1: the sample extracted by ethanol-water $(7: 3, \mathrm{v} / \mathrm{v})$; Sample 2: the sample reextracted from Sample 1 by ethyl acetate.

and L-AA) are shown in Figure 2. Compared with the results of the DPPH radical-scavenging activity, Sample 2 showed greater ABTS radical-scavenging activity than those of all the positive controls. There is a significant difference between the activities of Sample 1 and Sample 2. The results suggested that the components in Sample 2 might quench both ABTS and DPPH free radicals.

3.2.3. Reducing Power. It can be seen from the literature that the electron donating capacity of the component is a significant indicator of its potential antioxidant activity [38]. The antioxidant activities of the two samples and the three standard solutions (BHA, BHT, and L-AA), as reflected in their reducing power, are presented in Figure 3. In this assay, as well as in the first two assays, the reducing powers of the two samples and three positive controls were concentrationdependent. The reducing power of Sample 2 is just as strong as 


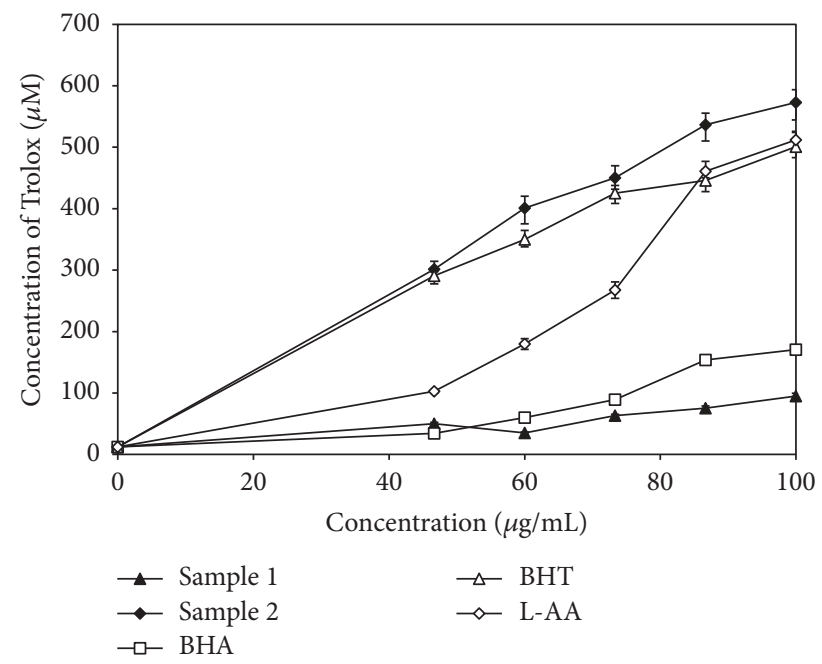

FIGURE 2: Free radical-scavenging activity of extracts from $C$. multiflorus sarcocarp measured by ABTS assay. Results are mean \pm SD $(n=3)$. Sample 1 : the sample extracted by ethanol-water $(7: 3$, v/v); Sample 2: the sample reextracted from Sample 1 by ethyl acetate.

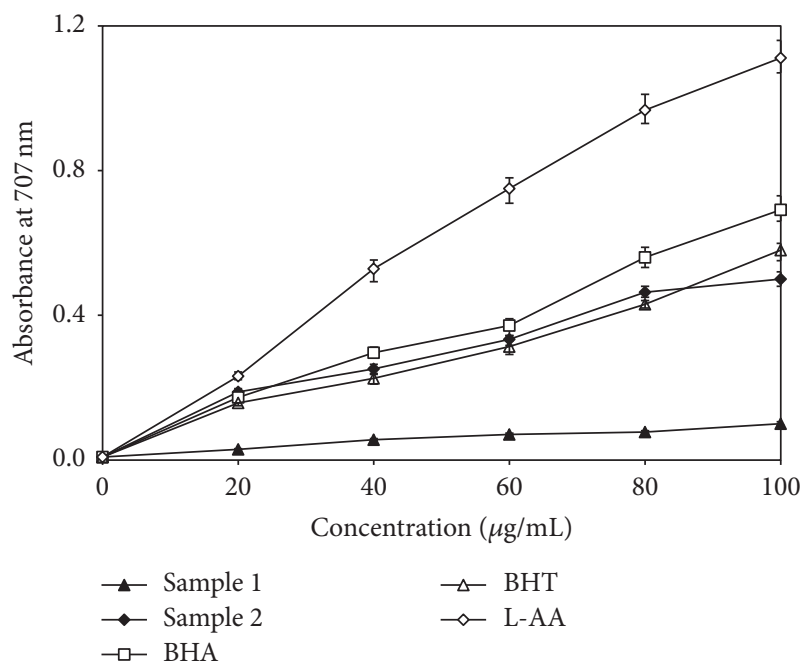

Figure 3: Antioxidant activity of extracts from C. multiflorus sarcocarp measured by reducing power assay. Results are mean \pm SD $(n=3)$. Sample 1: the sample extracted by ethanol-water $(7: 3, \mathrm{v} / \mathrm{v})$; Sample 2: the sample reextracted from Sample 1 by ethyl acetate.

those of BHA and BHT, although they were all inferior to that of L-AA. In addition, a much lower reducing power was found for Sample 1. It can be seen that the ethyl acetate fraction shows a much higher reducing power than the ethanol-water fraction. Based on this result, the ethyl acetate fraction can more easily transfer electrons to the reactive radicals and convert them to more stable, nonreactive species.

3.2.4. Ferric Reducing Antioxidant Power (FRAP). The FRAP assay is a quick and simple test for estimating the antioxidant capacity of any component in a reaction medium in terms of its reducing power. The antioxidant potentials of the extracts and fractions from the sarcocarp of C. multiflorus

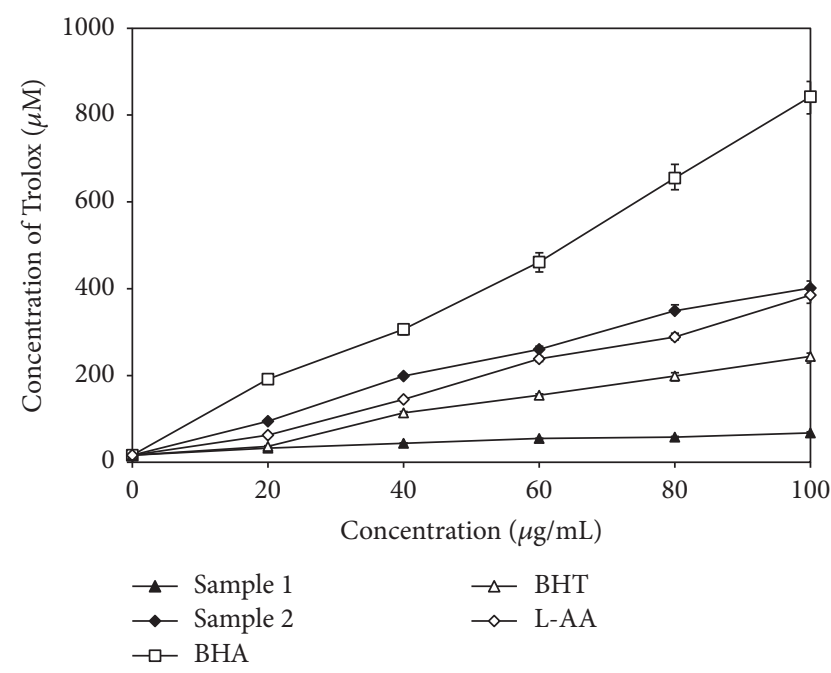

FIGURE 4: Antioxidant activity of extracts from the sarcocarp of $C$. multiflorus plus positive controls by using FRAP method. Results are mean $\pm \operatorname{SD}(n=3)$. Sample 1: the sample extracted by ethanol-water $(7: 3, \mathrm{v} / \mathrm{v})$; Sample 2 : the sample reextracted from Sample 1 by ethyl acetate.

were evaluated based on their capacity to reduce the TPTZ$\mathrm{Fe}^{3+}$ complex to the TPTZ-Fe ${ }^{2+}$ complex. The antioxidant potentials of Sample 1 and Sample 2 from the sarcocarp of C. multiflorus were estimated from their ferric ion-reducing activities as shown in Figure 4. The FRAP of Sample 2 is higher than L-AA, BHT, and Sample 1, although it is somewhat lower than that of BHA. Sample 1 showed the lowest ferric ion-reducing activities. Sample 2 had a strong ability to reduce $\mathrm{Fe}^{3+}$ to $\mathrm{Fe}^{2+}$.

3.2.5. Lipid Peroxidation in Sunflower Oil. The process of the lipid peroxidation consists of the fatty acids of the lipid reacting with the oxidant to generate primary oxidation products, which then decompose into small molecules such as dialdehydes, ketones, and acids, known as secondary oxidation products. These secondary oxidation products can give the oil an unpleasant odor. Malondialdehyde (MDA) is a secondary oxidation product, and it can be used as an indicator of the degree of lipid oxidation. In Figure 5, we can see that Sample 2 has a strong ability of preventing the peroxidation of sunflower oil. At the same concentration, the inhibitory effects on the oxidation of LDL of the samples decreased in the order BHA > Sample $2>$ L-AA $>$ BHT $>$ Sample 1. These results suggested that the compounds extracted by ethyl acetate can reduce the production of the oxidized intermediates during lipid peroxidation.

\section{Conclusions}

This work highlights the importance of C. multiflorus sarcocarp, which has been traditionally used as ornamental and medicinal plant in China and as a rich source of natural antioxidants. More specifically, the contents of total polyphenols $(155.1 \pm 7.5 \mathrm{mg} / \mathrm{g})$, total flavonoids $(226.9 \pm 11.0 \mathrm{mg} / \mathrm{g})$, 


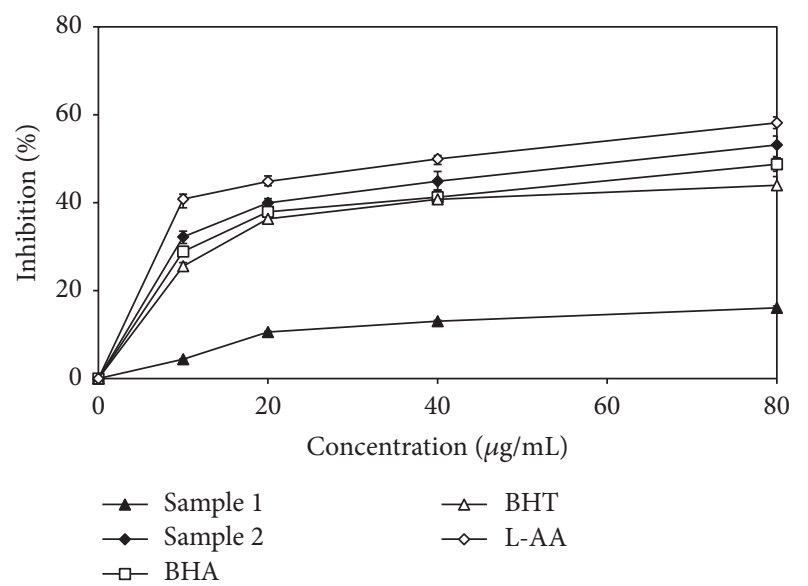

FIGURE 5: Thiobarbituric acid-reactive substances (TBARS) assay of extracts from the sarcocarp of $C$. multiflorus plus positive controls. Results are mean \pm SD $(n=3)$. Sample 1: the sample extracted by ethanol-water $(7: 3, \mathrm{v} / \mathrm{v})$; Sample 2 : the sample reextracted from Sample 1 by ethyl acetate.

and the oligomeric proanthocyanidins $(328.7 \pm 15.5 \mathrm{mg} / \mathrm{g})$ of the sample partitioned into ethyl acetate were higher (determined based on the dry powdered extracts) than the fractions of other solvents. Moreover, this sample showed the highest in vitro antioxidant and free radical-scavenging activities with the $\mathrm{IC}_{50}$ value of $42.72 \mu \mathrm{g} / \mathrm{mL}$ (based on second-degree polynomials equation: $Y=-0.0049 x^{2}+1.2322 x+6.3052$, $\left.R^{2}=0.9981\right)$ for DPPH radical-scavenging activities in vitro. Therefore, the present work provides powerful and useful information about the antioxidant activities of this plant.

\section{Conflicts of Interest}

The authors declare that they have no conflicts of interest regarding the publication of this article.

\section{Authors' Contributions}

Xiangping Liu and Jia Jia contributed equally to this work.

\section{Acknowledgments}

This work was supported by the National Natural Science Foundation of China (Grant no. NSFC31702169) and the Program for Young Scholars with Creative Talents in Heilongjiang Bayi Agricultural University (no. CXRC2017006).

\section{References}

[1] M. Martínez-Cayuela, "Oxygen free radicals and human disease," Biochimie, vol. 77, no. 3, pp. 147-161, 1995.

[2] C. Schöneich, "Reactive oxygen species and biological aging: A mechanistic approach," Experimental Gerontology, vol. 34, no. 1, pp. 19-34, 1999.

[3] T. Finkel and N. J. Holbrook, "Oxidants, oxidative stress and the biology of ageing," Nature, vol. 408, no. 6809, pp. 239-247, 2000.
[4] J. A. Olson and S. Kobayashi, "Antioxidants in health and disease: overview," Proceedings of the Society for Experimental Biology and Medicine, vol. 200, no. 2, pp. 245-247, 1992.

[5] Z. Liu, K. Mo, S. Fei, Y. Zu, and L. Yang, "Efficient approach for the extraction of proanthocyanidins from Cinnamomum longepaniculatum leaves using ultrasonic irradiation and an evaluation of their inhibition activity on digestive enzymes and antioxidant activity in vitro," Journal of Separation Science, vol. 40, no. 15, pp. 3100-3113, 2017.

[6] Y.-Z. Wang, S.-G. Fu, S.-Y. Wang, D.-J. Yang, Y.-H. S. Wu, and Y.-C. Chen, "Effects of a natural antioxidant, polyphenol-rich rosemary (Rosmarinus officinalis L.) extract, on lipid stability of plant-derived omega-3 fatty-acid rich oil," LWT-Food Science and Technology, vol. 89, pp. 210-216, 2018.

[7] Z. Liu and L. Yang, "Antisolvent precipitation for the preparation of high polymeric procyanidin nanoparticles under ultrasonication and evaluation of their antioxidant activity in vitro," Ultrasonics Sonochemistry, vol. 43, pp. 208-218, 2018.

[8] A. Kicel, P. Michel, A. Owczarek et al., "Phenolic profile and antioxidant potential of leaves from selected Cotoneaster Medik. species," Molecules, vol. 21, no. 6, article 688, 2016.

[9] A. Moure, J. M. Cruz, D. Franco et al., "Natural antioxidants from residual sources," Food Chemistry, vol. 72, no. 2, pp. 145171, 2001.

[10] N. Pellegrini, P. Simonetti, C. Gardana, O. Brenna, F. Brighenti, and P. Pietta, "Polyphenol content and total antioxidant activity of Vini novelli (young red wines)," Journal of Agricultural and Food Chemistry, vol. 48, no. 3, pp. 732-735, 2000.

[11] P. Pietta, P. Simonetti, C. Gardana, and P. Mauri, "Trolox equivalent antioxidant capacity (TEAC) of Ginkgo biloba flavonol and Camellia sinensis catechin metabolites," Journal of Pharmaceutical and Biomedical Analysis, vol. 23, no. 1, pp. 223-226, 2000.

[12] E. Akyuz, H. Şahin, F. Islamoglu, S. Kolayli, and P. Sandra, "Evaluation of phenolic compounds in Tilia rubra Subsp. caucasica by HPLC-UV and HPLC-UV-MS/MS," International Journal of Food Properties, vol. 17, no. 2, pp. 331-343, 2014.

[13] M. Amarowicz, R. B. Pegg, P. P. Kolodziejczyk, and J. Oszmiański, "Trihydroxyflavones from Scutellaria baicalensis: separation by a facile MEKC technique and comparison to an analytical HPLC method," Journal of Liquid Chromatography \& Related Technologies, vol. 27, no. 18, pp. 2847-2860, 2004.

[14] C.-S. Chang and J. I. Jeon, "Leaf flavonoids in Cotoneaster wilsonii (Rosaceae) from the island Ulleung-do, Korea," Biochemical Systematics and Ecology, vol. 31, no. 2, pp. 171-179, 2003.

[15] S. Khan, N. Riaz, N. Afza et al., "Antioxidant constituents from Cotoneaster racemiflora," Journal of Asian Natural Products Research, vol. 11, no. 1, pp. 44-48, 2009.

[16] C. Monier, E. Bossis, C. Chabanet, and R. Samson, "Different bacteria can enhance the micropropagation response of Cotoneaster lacteus (Rosaceae)," Journal of Applied Microbiology, vol. 85, no. 6, pp. 1047-1055, 1998.

[17] F. Les, V. López, G. Caprioli et al., "Chemical constituents, radical scavenging activity and enzyme inhibitory capacity of fruits from Cotoneaster pannosus Franch," Food \& Function, vol. 8, no. 5, pp. 1775-1784, 2017.

[18] I. V. Bartish, B. Hylmö, and H. Nybom, "RAPD analysis of interspecific relationships in presumably apomictic Cotoneaster species," Euphytica, vol. 120, no. 2, pp. 273-280, 2001.

[19] E. Palme, A. R. Bilia, V. De Feo, and I. Morelli, "Flavonoid glycosides from Cotoneaster thymaefolia," Phytochemistry, vol. 35, no. 5, pp. 1381-1382, 1994. 
[20] T. K. Chumbalov, L. T. Pashinina, and R. Z. Shukenova, "Flavonoids of Cotoneaster oligantha," Chemistry of Natural Compounds, vol. 11, no. 1, p. 99, 1975.

[21] A. M. D. El-Mousallamy, S. A. M. Hussein, I. Merfort, and M. A. M. Nawwar, "Unusual phenolic glycosides from Cotoneaster orbicularis," Phytochemistry, vol. 53, no. 6, pp. 699-704, 2000.

[22] L. T. Pashinina, T. K. Chumbalov, V. I. Sheichenko, and R. Z. Shukenova, "Dimeric proanthocyanidins of Cotoneaster oligantha," Chemistry of Natural Compounds, vol. 14, no. 2, pp. 166-172, 1978.

[23] J. Duan, B. Fu, B. Wang et al., "Wild fruit germplasm resources in Shanxi province," Journal of Fruit Science, vol. 25, no. 1, pp. $1-5,2008$.

[24] Y. Zhang, "Study on wild fruits gemplasm resources in Shandong province," Chinese Agricultural Science Bulletin, vol. 22, no. 7, pp. 516-520, 2006.

[25] Y. S. Velioglu, G. Mazza, L. Gao, and B. D. Oomah, "Antioxidant activity and total phenolics in selected fruits, vegetables, and grain products," Journal of Agricultural and Food Chemistry, vol. 46, no. 10, pp. 4113-4117, 1998.

[26] J. Zhishen, T. Mengcheng, and W. Jianming, "The determination of flavonoid contents in mulberry and their scavenging effects on superoxide radicals," Food Chemistry, vol. 64, no. 4, pp. 555559, 1999.

[27] F. Chen, X. Du, Y. Zu, L. Yang, and F. Wang, "Microwaveassisted method for distillation and dual extraction in obtaining essential oil, proanthocyanidins and polysaccharides by onepot process from Cinnamomi Cortex," Separation and Purification Technology, vol. 164, pp. 1-11, 2016.

[28] L. Yang, J.-M. Huang, Y.-G. Zu et al., "Preparation and radical scavenging activities of polymeric procyanidins nanoparticles by a supercritical antisolvent (SAS) process," Food Chemistry, vol. 128, no. 4, pp. 1152-1159, 2011.

[29] M. B. Arnao, A. Cano, and M. Acosta, "The hydrophilic and lipophilic contribution to total antioxidant activity," Food Chemistry, vol. 73, no. 2, pp. 239-244, 2001.

[30] X. Liu, J. Jia, L. Yang et al., "Evaluation of antioxidant activities of aqueous extracts and fractionation of different parts of Elsholtzia ciliata," Molecules, vol. 17, no. 5, pp. 5430-5441, 2012.

[31] I. F. F. Benzie and J. J. Strain, "The ferric reducing ability of plasma (FRAP) as a measure of antioxidant power the FRAP assay," Analytical Biochemistry, vol. 239, no. 1, pp. 70-76, 1996.

[32] K. D. Economou, V. Oreopoulou, and C. D. Thomopoulos, "Antioxidant activity of some plant extracts of the family labiatae," Journal of the American Oil Chemists' Society, vol. 68, no. 2, pp. 109-113, 1991.

[33] T. Balasubramanian, G. P. Senthilkumar, M. Karthikeyan, and T. K. Chatterjee, "Protective effect of ethyl acetate fraction of stereospermum suaveolens against hepatic oxidative stress in STZ diabetic rats," Journal of Traditional and Complementary Medicine, vol. 3, no. 3, pp. 175-181, 2013.

[34] C. Sánchez-Moreno, "Review: methods used to evaluate the free radical scavenging activity in foods and biological systems," Food Science and Technology International, vol. 8, no. 3, pp. 121137, 2002.

[35] A. Dapkevicius, T. A. Van Beek, G. P. Lelyveld et al., "Isolation and structure elucidation of radical scavengers from Thymus vulgaris leaves," Journal of Natural Products, vol. 65, no. 6, pp. 892-896, 2002.

[36] Z. Jia, F. Tao, L. Guo, G. Tao, and X. Ding, "Antioxidant properties of extracts from juemingzi (Cassia tora L.) evaluated in vitro," LWT-Food Science and Technology, vol. 40, no. 6, pp. 1072-1077, 2007.

[37] L. P. Leong and G. Shui, "An investigation of antioxidant capacity of fruits in Singapore markets," Food Chemistry, vol. 76, no. 1, pp. 69-75, 2002.

[38] J. Han, X. Weng, and K. Bi, "Antioxidants from a Chinese medicinal herb-Lithospermum erythrorhizon," Food Chemistry, vol. 106, no. 1, pp. 2-10, 2008. 

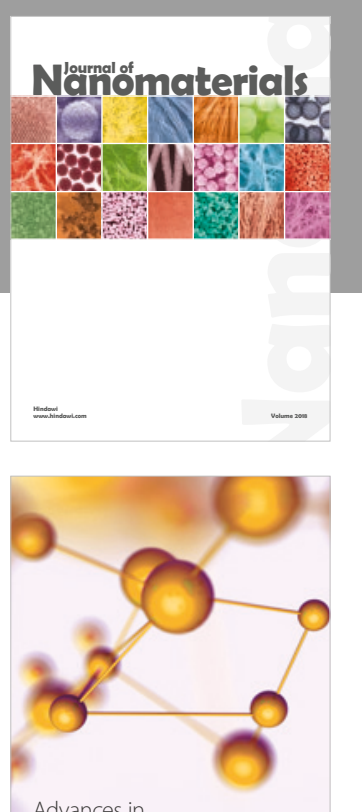

Physical Chemistry
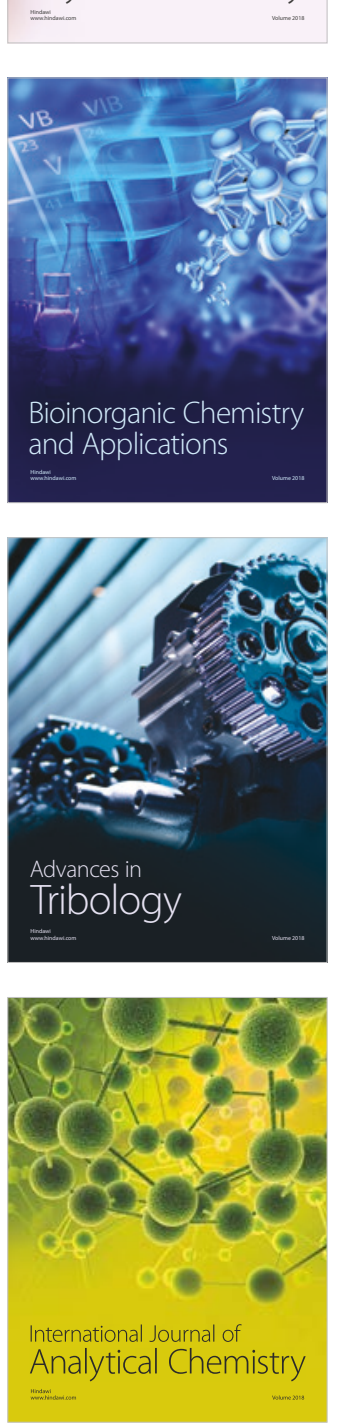

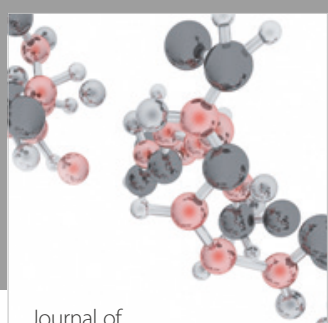

Analytical Methods

in Chemistry

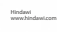

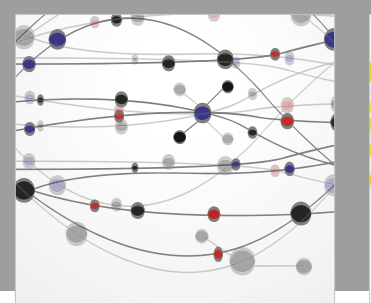

The Scientific World Journal

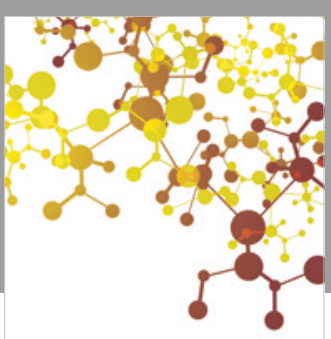

Journal of

Applied Chemistry
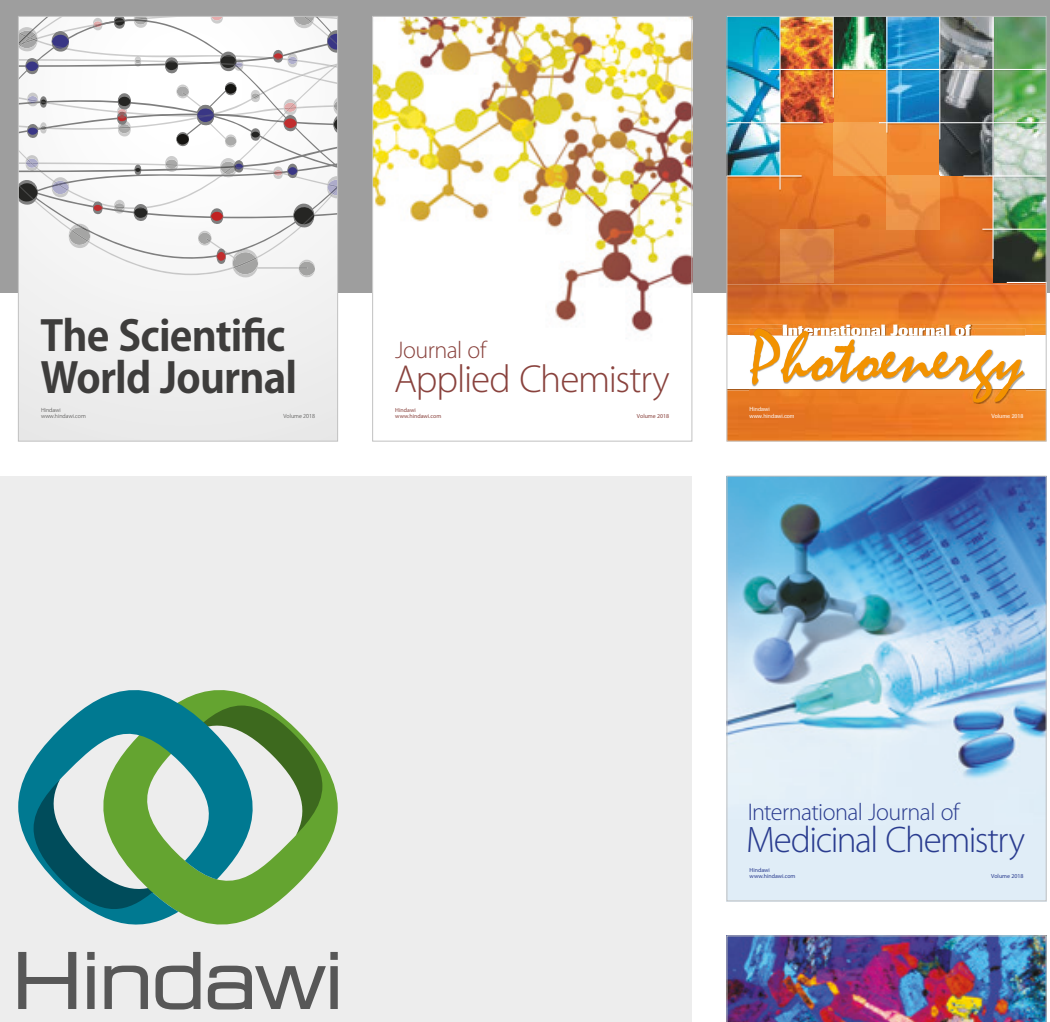

Submit your manuscripts at

www.hindawi.com
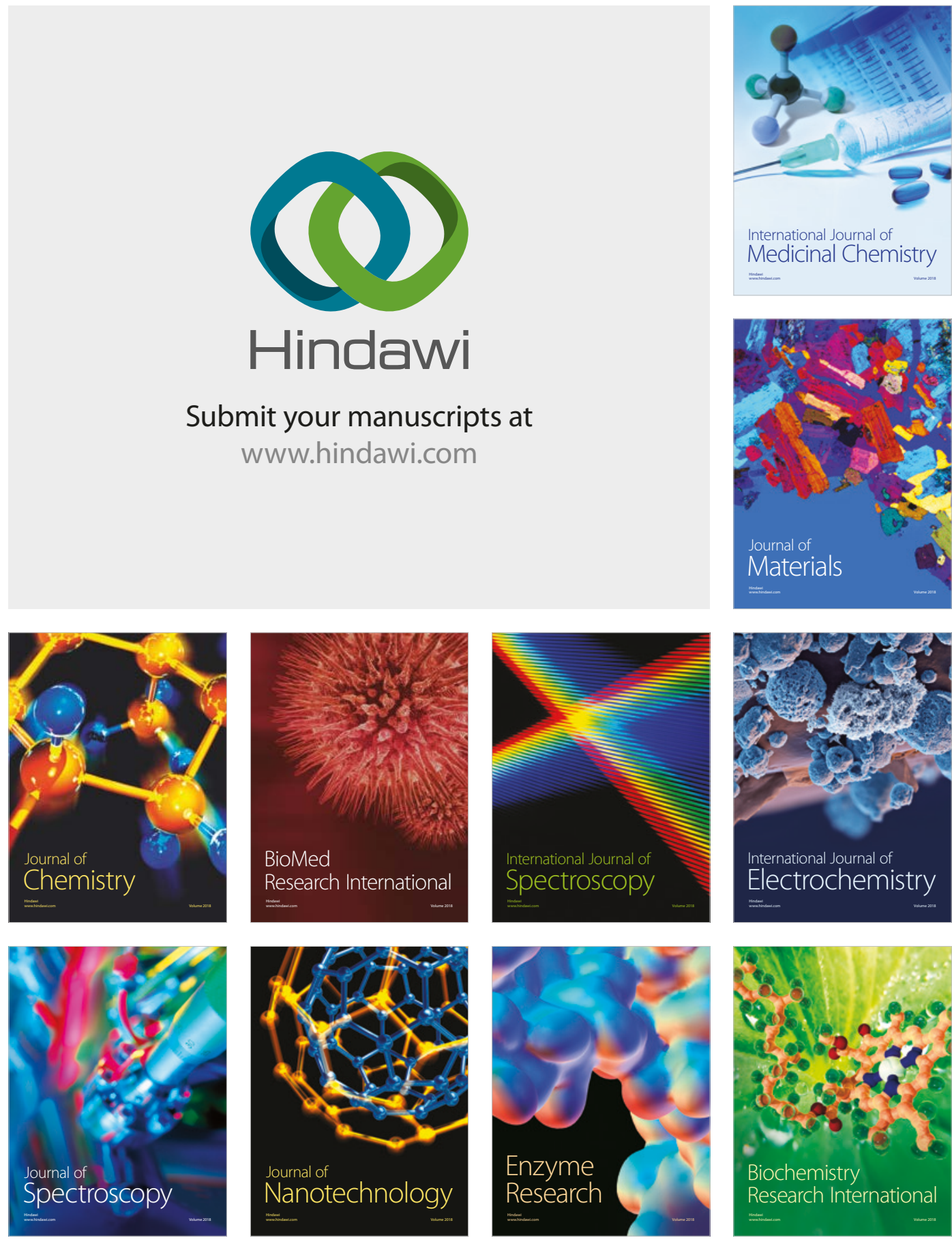
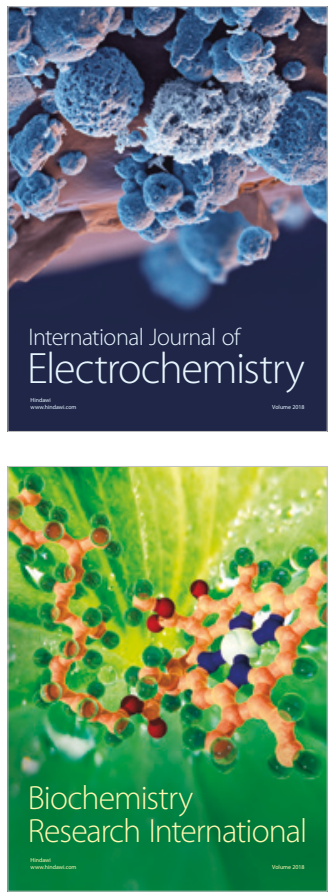